\title{
Clinical Efficacy of Aloe Vera Toothpaste on Periodontal Parameters of Patients with Gingivitis - A Randomized, Controlled, Single-masked Clinical Trial
}

\author{
Ferena Sayar ${ }^{1}$, Amir H Farahmand ${ }^{2}$, Maryam Rezazadeh ${ }^{3}$
}

\begin{abstract}
Aim and objective: This study aims to assess the effects of aloe vera toothpaste on dental plaques and gingivitis.

Materials and methods: This single-center, single-blind, randomized, two-period crossover study was performed on 20 dental students with a mean age of $24.5 \pm 4$ years with gingivitis. Subjects were randomly assigned to two groups $(n=10)$. After 14 days of trial period, plaque index (PI) and gingival index (GI) were assessed for each group. The first group used aloe vera toothpaste for 30 days and then their PI and $\mathrm{Gl}$ were recorded. A 2-week washout period was allowed and then the subjects used fluoride toothpaste for the next 30 days and underwent PI and GI assessment again. This order was reversed in group 2.

Results: Toothpaste-containing aloe vera showed no significant improvement in the GI and PI scores as compared with a fluoride-containing dentifrice. PI was $2.14 \pm 1.3$ at baseline and $1.84 \pm 1.02$ in 30 days $(p<0.098)$. GI was $0.62 \pm 0.74$ at baseline and $0.25 \pm 0.46$ at 30 days $(p<0.068)$. During the trial, no side effects were seen due to the use of aloe vera or fluoride toothpaste.

Conclusion: The effect of aloe vera toothpaste on PI and GI was similar to that of fluoride toothpaste and it seems that this toothpaste can be used as an alternative to a chemical toothpaste.

Clinical significance: The use of an aloe vera toothpaste in improving the progression of gingivitis can be evaluated.

Keywords: Aloe vera, Gingivitis, Oral hygiene, Toothpaste.

The Journal of Contemporary Dental Practice (2021): 10.5005/jp-journals-10024-3059
\end{abstract}

\section{INTRODUCTION}

Periodontal diseases are chronic infectious diseases characterized by a bacterial challenge that can provoke a destructive host response, leading to a clinical attachment loss $(\mathrm{AL})$ and ultimately possible tooth loss. ${ }^{1,2}$ Toothbrushing with toothpaste is the most common form of oral hygiene habit practiced by people in developed countries. Indeed, mechanical oral hygiene procedures are thought to be essential for proper plaque control and maintenance of periodontal health. ${ }^{3-7}$ Toothpaste is supposed to help in minimizing plaque accumulation, reinforcing teeth against caries, removing stains, removing food debris, and freshening the mouth. ${ }^{8,9}$ Toothpaste containing anti-plaque and anti-inflammatory agents would also improve plaque removal and help in overcoming the manual or mechanical shortcomings of brushing. ${ }^{10}$ Mechanical plaque removal by toothbrushing is the most commonly used technique for plaque control and prevention of periodontal diseases. However, for many people, optimal brushing is a challenge. Other oral hygiene measures, such as the use of toothpaste with different effective ingredients, have been suggested for these individuals to help them overcome the shortcomings of toothbrushing. In recent years, researchers have focused on the role of medicinal plants in decreasing gingival inflammation and assisting plaque removal with lower side effects. ${ }^{2,3,11}$ Aloe vera is a medicinal plant. Its use was first suggested by Hannibal in South Africa in 1750 BC. ${ }^{4}$ It belongs to the Liliaceae family and is a cactus plant. It is believed to have antimicrobial and anti-inflammatory properties and is used for the treatment of many inflammatory diseases like gingivitis. $3,4,8,9,10,12-16$ Sean et al. evaluated the antimicrobial effects of 14 herbal dentifrices and concluded that dental gels with various
${ }^{1}$ Department of Periodontics Sciences, Islamic Azad University, Tehran, Iran

${ }^{2}$ Department of Periodontics, Faculty of Dentistry, Tehran Medical Sciences, Islamic Azad University, Tehran, Iran

${ }^{3}$ Private Practice (General Dentist)

Corresponding Author: Amir $\mathrm{H}$ Farahmand, Department of Periodontics, Faculty of Dentistry, Tehran Medical Sciences, Islamic Azad University, Tehran, Iran, Phone: +989124040359 , e-mail: Perioimplant@hotmail.com

How to cite this article: Sayar F, Farahmand AH, Rezazadeh M. Clinical Efficacy of Aloe Vera Toothpaste on Periodontal Parameters of Patients with Gingivitis-A Randomized, Controlled, Single-masked Clinical Trial. J Contemp Dent Pract 2021;22(3):242-247.

Source of support: Nil

Conflict of interest: None

constituents, particularly aloe vera, had greater antimicrobial properties than other toothpastes. This property can explain the anti-inflammatory effects of a toothpaste containing aloe vera. ${ }^{17}$ Dental uses of aloe vera are added ${ }^{18}$; it is greatly helpful in the treatment of gum diseases, like gingivitis and periodontitis. ${ }^{19}$ It reduces bleeding, inflammation, and swelling of the gums. It is a potent antiseptic in pockets where normal cleaning is challenging, and its antifungal properties help greatly in the problem of denture stomatitis. ${ }^{20}$ Some studies have investigated the effects of herbal toothpaste, particularly aloe vera (Foramen Herbal Aloe, Spain) on periodontal parameters, yielding controversial results. ${ }^{21-29}$ The aim of the present study is to test whether the inhibiting effect of 
commercially available aloe vera toothpaste was as effective as a chemical toothpaste in the management of gingivitis.

\section{Materials and Methods}

Eligible participants were all 20 dental students with a mean age of $24.5 \pm 4$ years without systemic diseases, no periodontal treatment at least 6 months prior to the study, no use of systemic antibiotic and antiinflammatory drugs within the last 3 months with at least 20 natural teeth, nonsmokers, and not pregnant or lactating women. Subjects with orthodontic appliances, multiple bridges, partial dentures, and multiple caries and patients with known allergies to aloe vera or any of the components of the test product were excluded from the study. The study was registered at ClinicalTrials.gov as NCT02235532. The research was conducted according to the principles outlined in the Declaration of Helsinki on human medical experimentation. Written informed consent was obtained from all participants.

\section{Inclusion Criteria}

Gingivitis was defined in each patient as bleeding on probing (gentle) at $>30 \%$ and a gingival index $(\mathrm{Gl})^{30}$ of $\geq 1$ at $>60 \%$ of sites examined. All patients fulfilled the clinical criteria of having a pocket probing depth $\leq 3 \mathrm{~mm}$, clinical $\mathrm{AL}<1$, plaque index $(\mathrm{PI}) \geq 2$ as defined by Turesky et al., modification of Quigley-Hein $\mathrm{Pl}^{31,32}$ with no evidence of radiographic bone loss.

\section{Exclusion Criteria}

Periodontal treatment (nonsurgical) within the previous 6 months; systemic diseases; hypersensitive to ibuprofen; systemic antibiotic or anti-inflammatory drugs within the 3 months preceding the beginning of the study; pregnant or nursing females; smoking; no acute periodontal conditions, such as necrotizing periodontal diseases or periodontal abscesses; mouth rinses during the entire period of the study orthodontic treatments; use of removable dentures; and extensive dental restorations.

\section{Treatment Procedure and Clinical Evaluation}

Twenty participants were randomly assigned to two treatment groups, and one arm per patient was treated with aloe vera dentifrice (T1) or fluoride toothpaste (Signal, India), (T2) (Flowchart 1). Patients were asked not to perform any oral hygiene (including chewing gum) for 8 hours before the baseline and follow-up examinations. Patients were assessed for plaque using the $\mathrm{PI}^{31,32}$ and gingival inflammation using the $\mathrm{Gl}^{30}$ as well as for oral soft tissue status. Patients were instructed on proper toothbrushing technique and were given either the test or fluoride toothpaste along with a diary to record product usage and daily oral hygiene activities. Instructions for and demonstrations of modified Bass method of brushing were provided to the patients. ${ }^{33}$ The dentifrices were dispensed to the

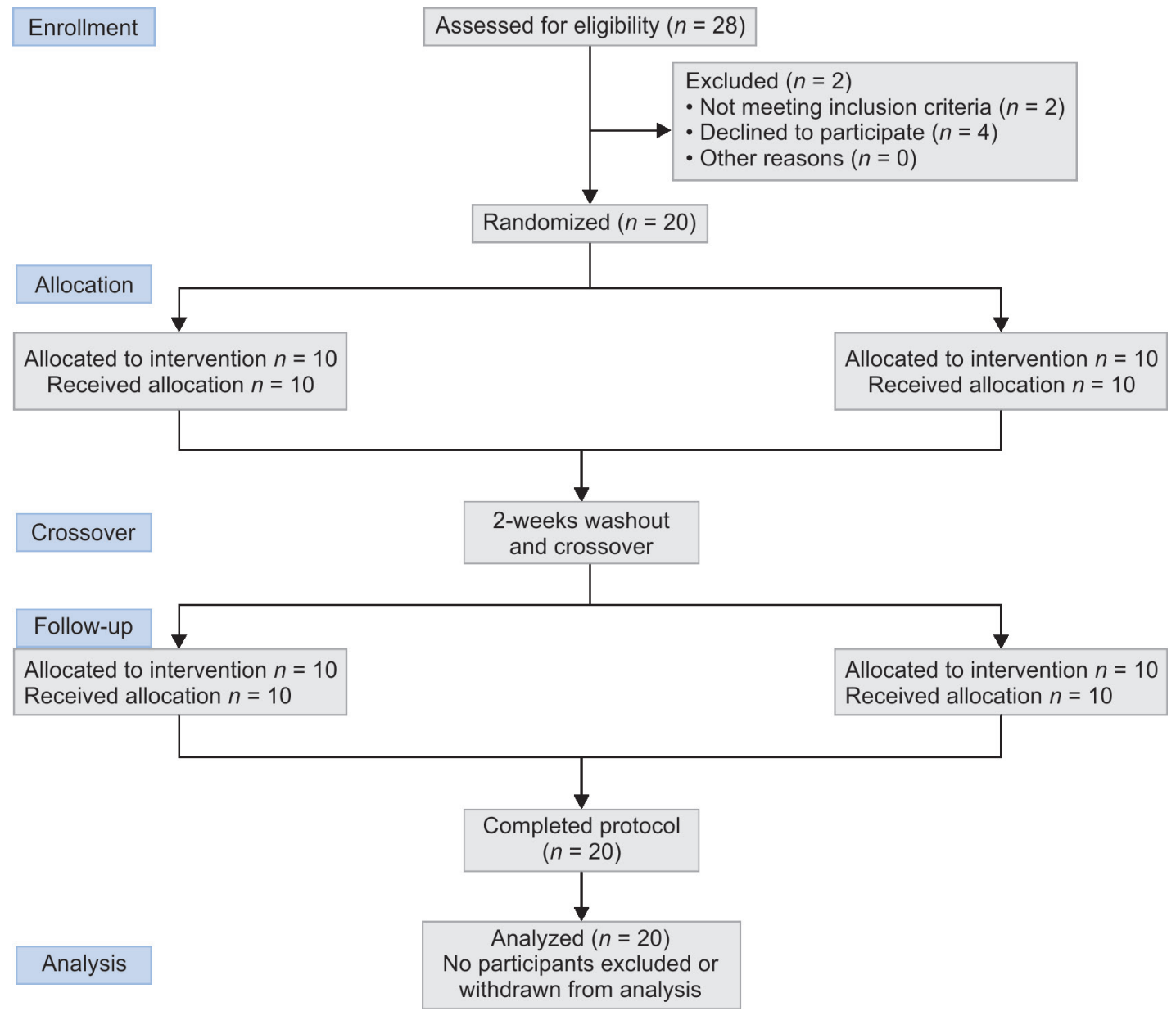

Flowchart 1: Flow diagram 
patients by a dental assistant not involved in the study (Department of Periodontics); all tubes had a plain white covering, labeled only with lot numbers to ensure proper masking, and a soft-bristled toothbrush was given to the participants. Patients were asked to refrain from all other unassigned forms of oral hygiene, including nonstudy toothbrushes or toothpaste, dental floss, chewing gum, or oral rinses during the study. Patients were assessed in the same dental unit under identical conditions at baseline and follow-up examinations; the intraexaminer reproducibility was tested by examining five patients out of the study twice with an 1-hour interval. Measurements were made blindly and separately. Then, the participants underwent baseline registration of gingival inflammation and plaque accumulation. Probing with Williams periodontal probe was done on six sites around each tooth except the third molars.

\section{Postprocedural Instructions}

All subjects had to undergo the assigned tooth cleaning regimens in a crossover manner for a treatment period of 30 days followed by a washout period of 14 days. Subjects were then told to brush with a toothpaste and toothbrush which they were using before the start of the study during the washout period. Clinical scores for each parameter were obtained by a single examiner. After the 30-day trial period, each subject returned for scoring of clinical parameters, baseline registration, and instruction for another (of the two) tooth cleaning regimen. The study continued in this manner for a period of 2.5 months, allowing each group to follow each of the two regimens for 30 days followed by a washout period of 14 days to avoid a carryover effect. The difference between the study groups was the sequence of using toothpaste; group A used the aloe vera toothpaste for the first 30-day period followed by the fluoride-containing toothpaste while group B used the fluoride toothpaste for the first 30-day period. The clinical examiner had no knowledge as to which study group patients were assigned at any time during the study period. At every visit, the occurrence of any undesirable side effects or adverse events that could be related to the treatment was recorded (Flowchart 2).

\section{Statistically Methods}

The sample size was determined on the basis of a previous study comparing scaling and root planing (SRP) with adjunctive aloe vera and fluoride toothpaste, where the difference in the number of residual pockets may decrease after crossover because everyone will have been treated with the toothpaste.

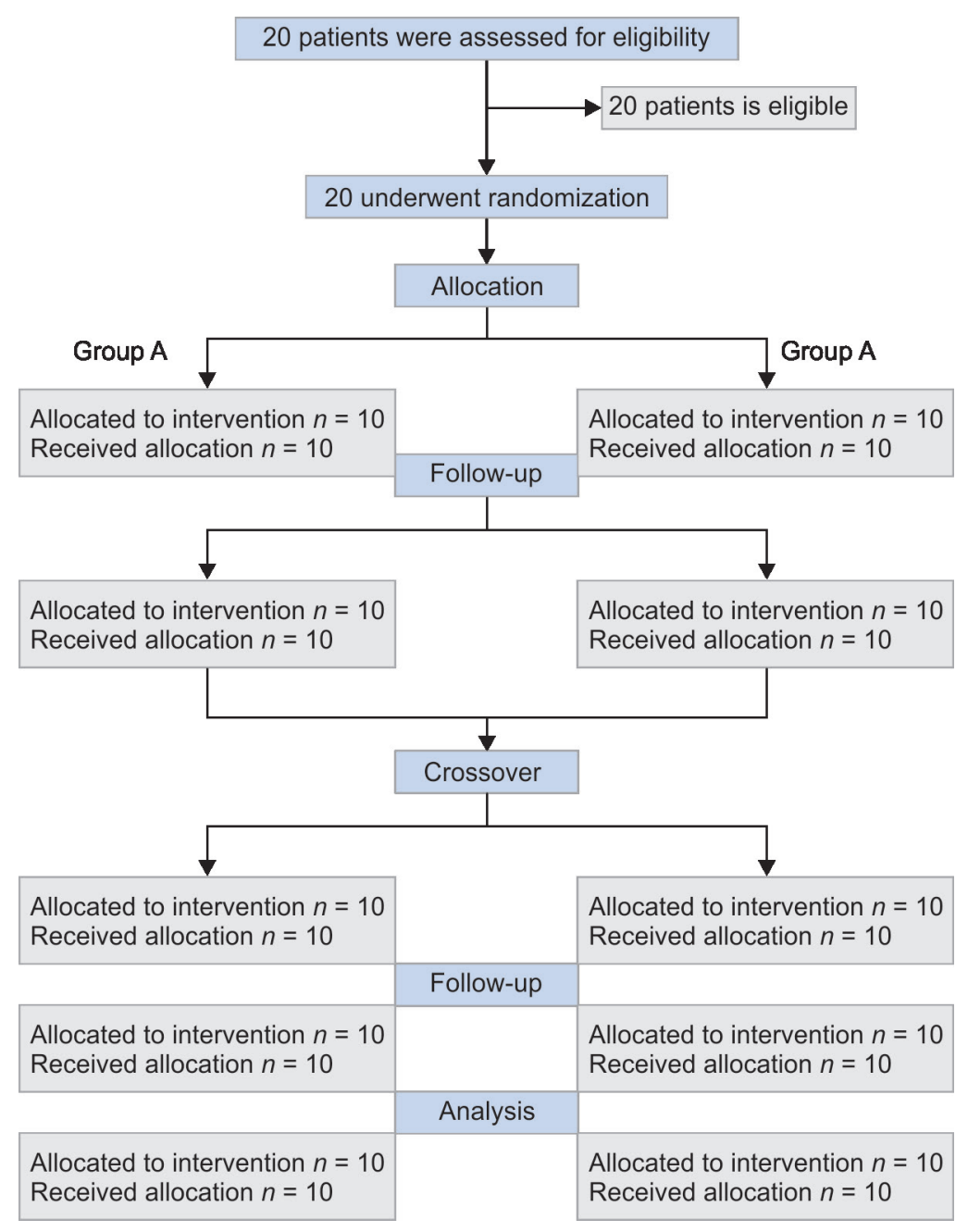

Flowchart 2: Study design 
The sample size was calculated using $a=0.05$ and the power $(1-\beta)=80 \%$. For variability $(\sigma=S D)$, the value of $0.5 \mathrm{~mm}$ was used, considering the reduction in $\mathrm{PI}$ of 0.79 from baseline to 1 month as the main outcome variable. Based on these data, the number of patients required to be enrolled to conduct this study was calculated as 10 patients per arm. However, considering the possibility of having a certain amount of dropout patients (10\%), the total number of requested patients was 12 per treatment group. Statistical software was used to analyze the data. The values of different parameters collected were expressed as means \pm standard deviation. Repeated measures two-way analysis of variance was used for the comparison of quantitative indices while Wilcoxon signed-rank test with $p$ value adjustment was applied for the comparison of qualitative variables. A $p$ value $<0.05$ was considered statistically significant. A $p$ value $<0.001$ was considered statistically significant.

\section{RESULT}

Twenty patients ( 10 males and 10 females) with a mean age of $24.5 \pm 4$ years completed the study and were included in the analysis. No patients abandoned the study after the treatment; group sample sizes were decided by power analysis with $90 \%$ power and a significance level of 0.05 . There was no significant difference between groups 1 and 2 with respect to the $\mathrm{PI}$ and $\mathrm{Gl}$ scores at baseline. There was a gradual decrease in the $\mathrm{PI}$ and $\mathrm{Gl}$ scores by the 1-week and 2-week-time intervals, respectively, in all two groups (Tables 1 and 2). The finding that showed the mean PI and $\mathrm{Gl}$ at different time points was based on the toothpaste used. $\mathrm{PI}$ and $\mathrm{GI}$ did not significantly change after the use of aloe vera toothpaste. PI was $2.14 \pm 1.3$ at baseline and $1.84 \pm 1.02$ in 30 days ( $p<0.098$ ); also $\mathrm{Gl}$ was $0.62 \pm 0.74$ at baseline and $0.25 \pm 0.46$ at 30 days $(p<0.068)$. No significant difference was found between the case and control groups at any time interval ( $p<0.07$ for $\mathrm{PI}$ and $p<0.308$ for $\mathrm{Gl}$ ). During the experiment, no side effects were seen due to the use of aloe vera or fluoride toothpaste (Tables 1 and 2).

\section{Discussion}

The purpose of this study is to estimate the clinical effects of an herbal dentifrice containing aloe vera on plaque and gingivitis compared to a fluoride-containing dentifrice over a period of 30 days. There was no significant variance between the aloe veracontaining toothpaste and the toothpaste containing fluoride in the reduction of PI and GI. The outcomes of this current study are in agreement with those of De Oliveira et al. who found that

Table 1: The mean PI at baseline and 1 month time points in the two groups

\begin{tabular}{lllll}
\hline & Mean $\pm S D$ at & Mean $\pm S D$ at & & \\
Group/time point & dayzero & month & $p$ value & $p$ value \\
\hline Control & $2.31 \pm 1.02$ & $1.94 \pm 0.52$ & $<0.19$ & 0.07 \\
Test & $2.14 \pm 1.3$ & $1.84 \pm 1.02$ & $<0.098$ & \\
\hline
\end{tabular}

Table 2: The mean Gl at basline and 1 month time points in the two groups

\begin{tabular}{lllll}
\hline & $\begin{array}{l}\text { Mean } \pm \text { SD at } \\
\text { baseline }\end{array}$ & $\begin{array}{l}\text { Mean } \pm \text { SD at } \\
1 \text { month }\end{array}$ & pvalue & p value \\
\hline Control & $0.47 \pm 0.63$ & $0.31 \pm 0.48$ & $<0.17$ & 0.308 \\
Test & $0.62 \pm 0.74$ & $0.25 \pm 0.46$ & $<0.068$ & \\
\hline
\end{tabular}

both a toothpaste containing aloe vera and a dentifrice containing fluoride resulted in a significant reduction of plaque and gingivitis, but no statistically significant difference was observed between them. ${ }^{14}$ Manual control of dental plaque has been clearly shown to retard the advancement of gingivitis and periodontal diseases. ${ }^{34,35}$ Axelsson and Lindhe described that noncompliant patients showed marks of persistent disease processes; due to the variation of simple mechanical control of plaque accumulation, several chemotherapeutic factors have been combined into home-use products to control plaque and gingivitis. ${ }^{35}$ Pradeep exhibited the influence of aloe vera toothpaste on $\mathrm{Gl}$ and $\mathrm{PI}$ improvement as well as microbiological counts were identical to a toothpaste containing triclosan, while on evaluation of placebo toothpaste a noteworthy improvement was achieved by aloe vera toothpaste. It was demanded that acetylated mannans, gel polysaccharides from aloe vera, had the main role in inflammation control. ${ }^{22}$ As a consequence of problems with proper mechanical control of plaques among the population, altered ingredients have been merged in mouthwashes and dentifrices to better control the oral microorganisms. Aloe vera has about 75 possibly active components, in which polysaccharides are considered to have anti-inflammation and immunomodulation effects. ${ }^{13}$ Also, antioxidant properties have been shown in aloe vera gel which could be important to control and for the treatment of periodontal diseases. ${ }^{14}$ Abdulwahab stated that regular application of herbal extract toothpaste through 42 days provided a significant decline of dental plaque buildup and a lot of gingival inflammation signs, such as gingival bleeding, and these agents have a bactericidal response against most of the periodontal pathogens without a negative effect on the normal microflora. ${ }^{37}$ Because of the inconsistency of simple mechanical control of plaque accumulation, a number of chemotherapeutic agents have been merged into home-use products to control plaques and gingivitis. These agents have mostly been incorporated into either mouth rinses or toothpaste. The main action of these agents has been focused on their antimicrobial action. There have been a number of active ingredients incorporated into various dentifrices. ${ }^{35}$ The importance of plaque control is documented in the literature. ${ }^{36,38}$ The use of the correct method to do oral hygiene seems the best way to control the composition of subgingival bacteria. ${ }^{39,40}$ Karim et al. showed that aloe vera mouth rinse is equally effective in reducing periodontal indices as chlorhexidine, and also indicated that aloe vera may prove to be an efficient mouthwash owing to its ability in reducing periodontal indices. ${ }^{41}$ Saito et al. ${ }^{42}$ proposed that a glycoprotein, aloctin $\mathrm{A}$, which was isolated from Aloe arborescens Miller, markedly prevents arthritis in rats and carrageenan-induced edema in rats. Hutter et al. ${ }^{43}$ identified an anti-inflammatory agent C-glucosyl chromone from Aloe barbadensis. Aloe vera is known to contain several active ingredients, including a carboxypeptidase that inactivates bradykinin in vitro, salicylates, and a substance that inhibits thromboxane (TX) synthesis. ${ }^{44}$ Yagi et al. in a study found that three aloesin derivatives from aloe (namely isorabaichromione, feruloylaloesin, and p-coumaroylaloesin) have potent free radical and superoxide anion scavenging possessions. ${ }^{45}$ Heggers and Robson demonstrated that barbolin and aloe emodin in aloe vera block prostaglandin synthesis. The decrease in the $\mathrm{Gl}$ can be assigned to the presence of sterols as anti-inflammatory agents and lupeol as an antiseptic analgesic. ${ }^{46}$ It was found that aloesin compounds inhibited cyclooxygenase-2 and TXA2 synthase, which clarifies the healing effects of aloe vera. ${ }^{45,47}$ The creation of reactive oxygen kinds is an essential protective mechanism against diseases associated with phagocytic infiltration and is the 
host defense mechanism against bacterial pathogens ${ }^{48}$; however, Moghaddam et al. exhibited that as there was no significant difference in $\mathrm{Pl}$ in three phases between control and experimental groups, topical usage of aloe vera gel could be considered an adjunctive medication with SRP for chronic periodontitis ${ }^{49}$. Therefore, Hudwekar et al. revealed that the use of aloe vera extract was effective in significantly improving the healing scores after periodontal flap surgery in the 1 st week, ${ }^{50}$ and also Elsadek et al. ${ }^{51}$ mentioned that the use of antimicrobial photodynamic therapy plus aloe vera gel resulted in decreasing periodontal inflammation; in addition, the aloe vera gel provided added advantage in decreasing the bleeding index. Our study was conducted on dental students and the obtained results highlighted the important role of correct toothbrushing technique. The correct technique of toothbrushing attenuates the role of the type of toothpaste used. Future trials are necessary to be implemented on a larger sample size selected from the general population and for a longtime study.

\section{Conclusion}

The use of natural herbal preparations in oral health care continues to be popular, and aloe vera dentifrice may be a useful addition; therefore, it could be used for the improvement of plaque and gingival status. Additional long-term prospective studies are needed to confirm the results achieved in this study.

\section{Clinical Significance}

The use of an aloe vera toothpaste in improving the progression of gingivitis can be evaluated.

\section{Acknowledgments}

The authors wish to thank the participating undergraduate dental students in this study and also thank Dr. Mohammad Javad KharaziFard, a statistician, Islamic Azad University, Dental Branch of Tehran, for performing the required statistics. This study was tendentiously supported by Ferena Sayar by a grant and by providing materials used in this investigation for free.

\section{References}

1. Silva N, Abusleme L, Bravo D,Dutzan N JGarcia-Sesnich J, Rolando Vernal Marcela Hernández, Jorge Gamonal. Host response mechanisms in periodontal diseases. J Appl Oral Sci May-Jun 2015;23(3):329-55.

2. De la Rosa M, Zacarias Guerra J, Johnston DA, Radike AW. Plaque growth and removal with daily toothbrushing. J Periodontol 1979; 50:661-664.

3. Anneroth G, Poppleman A. Histological evaluation of gingival damage by toothbrushing. An experimental study in the dog. Acta Odontologica Scandinavica 1975; 33: 119-27.

4. Sangnes $G$. Traumatization of teeth and gingivae related to habitual tooth cleaning. Review article. Journal Clinical Periodontology 1976; 3:94-103.

5. Sangnes G, Gjermo P. Prevalence of oral soft and hard tissue lesions related to mechanical tooth cleaning procedures. Community Dentistry and Oral Epidemiology 1976; 4:77-83.

6. Sandholm L, Niemi ML, Ainamo J. Identification of soft tissue brushing lesion. A clinical and scanning electron microscopic study. Journal of Clinical Periodontology1982; 9:397-401.

7. Niemi ML, Sandholm L, Ainamo J. Frequency of gingival lesions after standardized brushing as related to stiffness of toothbrush and abrasiveness of toothpaste. Journal of Clinical Periodontology 1984; 11:254-61.
8. Forward GC, James AH, Barnett P, Jackson RJ. Gum health product formulations: What is in them and why? Periodontol 2000; 1997:15: 32-9.

9. Rubido S, García-Caballero Lucía, Abeleira MT, Limeres J, García M, Diz P. Effect of che wing an apple on dental plaque removal and on salivary bacterial viability. PLoS One. 2018 Jul 18;13(7):e0199812.

10. Mandel ID. Chemotherapeutic agents for controlling plaque and gingivitis. J Clin Periodontol 1988; 15:488-98.

11. Jepsen $\mathrm{S}$. The role of manual toothbrushes in effective plaque control: advantages and limitations. In: Lang, N.P., Attström, R. \& Löe, H., eds. Proceedings of the European Workshop on Mechanical Plaque Control. London: Quintessence, 1998; 121-137.

12. Samuels N, Grbic JT. Effect of an herbal mouth rinse in preventing periodontal inflammation in an experimental gingivitis model: a pilot study. Compend Contin Educ Dent. 2012:33(3):204-6,208-211.

13. Ashwini Somu C, Ravindra S. Efficacy of an herbal exact gel in the treatment of gingivitis. J Ayurveda Inter Med 2012;3(2):85-90.

14. De Oliveira SM, Torres TC, Pereira SL, et al. Effect of a dentifrice containing Aloe vera on plaque and gingivitis control. A double-blind clinical study in humans. J Appl Oral Sci 2008;16(4):293-296.

15. Eshun K, He Q. Aloevera; a valuable ingredient for the food, pharmaceutical and cosmetic industries. Crit Rev Food Sci Nutr 2004;44(2):91-96. DOI: 10.1080/10408690490424694.

16. Fani MM, Kohanteb J. Inhibitory activity of aloe vera on some clinically isolated cariogenic and periodontopathic bacteria. J Oral Sci 2012;54(1):15-21. DOI: 10.2334/josnusd.54.15.

17. Lee SS, Zhang W, Li Y. The antimicrobial potential of 14 natural herbaldentifrices. J Am Dent Assoc 2004;135(8):1133-1141.

18. Grindlay $D$, Reynolds $T$. The Aloe vera phenomenon: a review of the properties and modern uses of leaf parenchyma gel. J Ethnopharmacol 1986;16(2-3):117-151.

19. Sudworth R. The use of Aloe Vera in dentistry. Philadelphia: Positive Health Publications Ltd; 2002.

20. Tello CG, Ford P, lacopino AM. In vitro evaluation of complex carbohydrate denture adhesive formulations. Quintessence Int1998 Sep ;29(9):585-93.

21. Goerge J, Hegde S, Rajesh KS, et al. The efficacy of a herbal-based toothpaste in the control of plaque and gingivitis. Indian J Dent Res 2009;20(4):480-482.

22. Pradeep AR, Agarwal E, Niak SB. Clinical and microbiologic effect of commercially available dentifrice containing aloe vera:A randomized controlled clinical trial. J Periodontol 2012;83(6):797-804.

23. Ponnutis $\mathrm{CM}$, Maltas J. Clinical effect of an herbal dentifrice on the control of plaque and gingivitis. Pesqui Odontol Bras 2003;17(4):314- 318.

24. Vogler BK, Ernst E. Aloe vera: a systematic review of its clinical effectiveness. Br J Gen Pract1999 Oct;49(447):823-8.

25. Choi SW, Son BW. The wound-healing effect of a glycoprotein fraction isolated from aloe vera. Br J Dermatol 2001;145(4):535-545.

26. Reuter J, Jocher A. Investigation of the anti-inflammatory potential of aloe vera gel (97.5) in the ultraviolet erythema test. Skin Pharmacol Physiol 2008;21(2):106-110.

27. MaiaFilho AL, Villaverde AB. Comparative study of the topical application of Aloe vera gel, therapeutic ultrasound and phonophoresis on the tissue repair in collagenase-induced rat tendinitis. Ultrasound Med Biol 2010;36(10):1682-1690.

28. Park MY, Kwon HJ,Sung MK. Ditaryaloein, aloesin, or aloe-gel extract anti-inflammatory activity in arat colitis model. Life Sci 2011;88(1112):486-492

29. George D, Bhat SS, Antony B. Comparative evaluation of the antimicrobial efficacy of aloe vera tooth gel and two popular commercial toothpastes: an in- vitro study. GenDent. MayJun2009;57(3):238-41.

30. Loe H, Silness J. Periodontal diseases in pregnancy. I. Prevalence and severity. Acta Odontol Scand 1963;21:533-551.

31. Quigley GA, Hein JW. Comparative cleansing efficiency of manual and power brushing. J Am Dent Assoc 1962;65:26-29.

32. Turesky S, Gilmore ND, Glickman I. Reduced plaque formation by the chloromethyl analogue of vitamin C. J Periodontol 1970;41(1):41-43. 
33. Disyam L. A comparison of three methods of toothbrushing: roll, modified Bass and scrub technique. J Dent Assoc Thai Jan-Feb 1987; 37(1):1-10.

34. Villalobos OJ, Salazar CR, Sánchez GR. Efecto de un enjuague bucal compuesto de aloe vera en la placa bacteriana e inflamación gingival. Acta Odontol Venez. 2001; 39(2):16-24.

35. Axelsson $P$, Lindhe J. The significance of maintenance care in the treatment of periodontal disease. J Clin Periodontol 1981;8(4): 281- 294.

36. Wilson TG Jr, Glover ME, Malik AK, et al. Tooth loss in maintenance patients in a private periodontal practice. J Periodontol 1987;58(4): 231-235.

37. Al-kholani Al. Comparison between the Efficacy of Herbal and Conventional Dentifrices on Established Gingivitis. Dent Res J (Isfahan). Spring 2011;8(2):57-63.

38. Cobb CM. Non-surgical pocket therapy: mechanical. Ann Periodontol 1996; 1(1):443-490.

39. McNabb H, Mombelli A, Lang NP. Supragingival cleaning 3 times a week. The microbiological effects in moderately deep pockets. J Clin Periodontol 1992;19(5):348-356.

40. Hellstrom MK, Ramberg P, Krok L, et al. The effect of supragingival plaque control on the subgingival microflora in human periodontitis. J Clin Periodontol 1996;23(10):934-940.

41. Karim B, Bhaskar DJ, Agali C, et al. Effect of Aloe vera mouthwash on periodontal health: triple blind randomized control trial. Oral Health Dent Manag 2014;13(1):14-19.

42. Saito $H$, Ishiguro $T$, Imanishi $K$, et al. Pharmacological studies on a plant lectin aloctin A. II. Inhibitory effect of aloctin A on experimental models of inflammation in rats. Jpn J Pharmacol 1982;32(1):139-142.

43. Hutter JA, Salman M, Stavinoha WB, et al. Antiinflammatory C-glucosyl chromone from Aloe barbadensis. J Nat Prod 1996;59(5):541-543.

44. Klein AD, Penneys NS. Aloe Vera. J Am Acad Dermatol 1988;18(4 Pt 1): 714-720.

45. Yagi A, Kabash A, Okamura N, et al. Antioxidant, free radical scavenging and anti-inflammatory effects of aloesin derivatives in Aloe vera. Planta Med 2002;68(11):957-960.

46. Heggers JP, Robson MC. Burns: prostaglandins and thromboxane. Crit Care Clin 1985;1:59-77.

47. Vazquez B, Avila G, David S, et al. Anti-inflammatory activity of extracts from Aloe vera gel. J Ethnopharmacol 1996;55(1):69-75.

48. Fialkow $L$, Wang $Y$, Downey GP. Reactive oxygen and nitrogen species as signaling molecules regulating neutrophil function. Free Radic Biol Med 2007;42(2):153-164.

49. Ashouri Moghaddam A, Radafshar G, Jahandideh Y, Kakaei N. Clinical evaluation of effects of local application of aloe vera gel as an adjunct to scaling and root planning in patients with chronic periodontitis. J Dent (Shiraz) 2017;18(3):165-172.

50. Hudwekar AD, Beldar A, Murkute $S$, et al. Aloe vera on wound healing after periodontal flap surgery in chronic periodontitis patient: $A$ randomized control trial. J Oral Res Rev 2019;11(2):72-76.

51. ElsadekMF,AhmedBM, Eskandrani RM, etal.Clinical andmicrobiological outcomes of topical aloe vera gel vs. photochemotherapy as an adjunct to non-surgical periodontal treatment in periodontitis. Planta Med Int Open 2020;7(3):e100-e105. 